\title{
La escuela de Celestina de Salas Barbadillo o la herencia interrumpida
}

\section{Salas Barbadillo's La escuela de Celestina, or the Interrupted Heritage}

\section{Enrique García Santo-Tomás}

University of Michigan, Ann Arbor

ESTADOS UNIDOS

enriqueg@umich.edu

[Hipogrifo, (issn: 2328-1308), 5.1, 2017, pp. 249-261]

Recibido: 03-06-2015 / Aceptado: 28-06-2015

DOI: http://dx.doi.org/10.13035/H.2017.05.01.16

Resumen. Poco se ha escrito sobre La escuela de Celestina y el hidalgo presumido (1620), una de las escasas comedias que nos ha dejado Alonso Jerónimo de Salas Barbadillo. El presente ensayo propone leer esta pieza como inserta en la tradición paródica de los gallos y vejámenes universitarios, que le sirve al autor para reflexionar sobre el papel de la alta cultura en la sociedad áurea, sobre el carácter ceremonial del conocimiento y, en última instancia, sobre la herencia de determinados mitos literarios, que queda aquí interrumpida en esta reescritura de la figura celestinesca.

Palabras clave. La escuela de Celestina y el hidalgo presumido, Salas Barbadillo, parodia, vejamen universitario, transmisión del conocimiento.

Abstract. Little has been written on La escuela de Celestina y el hidalgo presumido (1620), one of the few comedies penned by Alonso Jerónimo de Salas Barbadillo. In this essay I read this piece as part of a tradition of parodies of the famous academic exercises known as gallos and vejámenes, so frequent in the universities of the time. Through humorous inversion, Salas leads us to formulate new questions on the role of high culture, on the nature of true knowledge and, ultimately, on the transmission of specific literary myths - a transmission that is here interrupted by the rewriting of the Celestinesque character.

Keywords. La escuela de Celestina y el hidalgo presumido, Salas Barbadillo, Parody, Vejamen, Transmission of Knowledge. 
Comedia de la escuela de Celestina y el hidalgo presumido, publicada en la imprenta de Andrés de Porras en 1620, es una de las pocas comedias que nos han llegado del escritor madrileño Alonso Jerónimo de Salas Barbadillo (1561-1635). Constituye, según adelanta su autor en la dedicatoria Al vulgo, la primera entrega de una colección titulada Comedias españolas - a la que debía seguir la pieza El tramposo con las damas, castigado con lo mismo, de la que existe una edición de 1774 atribuida erróneamente a Cubillo de Aragón- que el autor planeó pero que nunca llevó a término'. Es esta Celestina, de hecho, una recreación apenas conocida $^{2}$, perteneciente a la discreta actividad teatral de un narrador del cual se había escrito relativamente poco hasta fechas recientes. Toda esta inercia adversa hace del estudio de esta comedia un atractivo envite para la crítica contemporánea, más aún teniendo en cuenta que La escuela de Celestina es una pieza tan peculiar en sus fines como atípica en sus contenidos: si ya desde el título nos anuncia un decidido homenaje a su más excelso modelo, lo cierto es que su temática la desmarca considerablemente de éste, dando lugar, en cierta manera, a esta herencia interrumpida, a esta reflexión con la que el madrileño, se podría decir, nos recuerda que el modelo tradicional está necesitado de nuevos elementos más cercanos a la realidad presente, de una verdadera puesta al día. Como resultado, Salas abre en esta pieza una deliberada brecha con sus antecesores ${ }^{3}$, al incluir en ella ingredientes habituales de la prosa del momento como serán la parodia de ciertas costumbres urbanas y la sátira de diversos tipos sociales, resortes más típicos de la novela corta y que fueron muy comunes en su propia creación. La extrañeza que produce la lectura de esta 'Celestina catedrática' ha suscitado todo tipo de lecturas, algunas más afortunadas que otras, por críticos excesivamente preocupados por categorizarlo todo: Francisco R. de Uhagón la calificó, en su breve prólogo de 1902, de «novela dialogada» ${ }^{4}$; Emile Arnaud se preguntaba en su tesis doctoral de 1977, dedicada a la obra completa del madrileño: "La Escuela de Celestina est-elle une "comedia"?»5; y, más recientemente, el hispanista cubano-americano Antonio Cao avanzó una posible respuesta al calificarla de «anti-comedia» ${ }^{6}$. Son tres apreciaciones, creo yo, un tanto baladíes, en la medida en que el mismo Salas anuncia ya en el título que nos encontramos ante una comedia, pero ante una comedia muy de su musa, un tanto diferente de los usos del tiempo tal y como lo fue gran parte de su produc-

1. Salas escribe que «[E]stas Comedias antes dadas a la estampa que al teatro te ofrezco cada una suelta, así como van saliendo de la emprenta, porque sea eleción tuya el juntarlas, si acaso te agradaren todas... la presente, intitulada La escuela de Celestina, y el hidalgo presumido, era la primera en los originales, y así en la impresión se le ha guardado el mismo lugar» (La escuela de Celestina, p. 15). No hay rastro de esos «originales», como bien nos recuerda Cassol, 2011. En los versos finales de la pieza se anuncia una segunda parte, que al parecer no fue compuesta nunca. La pieza pubicada en 1774 sale con el título El tramposo con las damas y castigo merecido.

2. Ninguno de los críticos que ha estudiado la genealogía celestinesca a lo largo del siglo XVII, como han sido por ejemplo Pierre Heugas, Roberto González Echevarría o Ignacio Arellano, se han detenido en este texto.

3. Ver, de entre las varias aportaciones al tema, Torres, 2004

4. Francisco R. de Uhagón, 1902, p. 7.

5. Arnaud, 1977, p. 578

6. Cao, 1992, p. 799. 
ción literaria?. Las siguientes páginas sirven, por tanto, para situar esta pequeña joya salasiana en el lugar que le corresponde, y para ello propongo una lectura de La escuela de Celestina que la sitúa en la tradición paródica de determinados ceremoniales académicos del momento manifestada en los conocidos vejámenes de grado y gallos universitarios, y que justifican tanto el sentido burlesco del aparente oxímoron del título como la extensa crítica a tipos y usos sociales cortesanos que se lleva a cabo en sus tres actos. La parodia de Celestina como catedrática anuncia un cierto desgaste de la figura mítica, al tiempo que se erige como un ataque sin ambages contra el ceremonial vacuo del mundo universitario que para 1620 contaba ya, como indicaré más adelante, con una rica tradición a sus espaldas.

La praxis teatral de Salas, como prácticamente todo el resto de su obra, es el testimonio de una constante experimentación en la que se manipulan con mayor o menor éxito los diferentes géneros literarios en boga durante la primera mitad del $\mathrm{XVII}{ }^{9}$. Se trata éste de un rasgo que responde al continuo afán de innovar y probar nuevos esquemas teóricos para tratar asuntos ya clásicos como la hipocresía, la obsesión por las apariencias, el poder del dinero, el medro frustrado o inmerecido, las manipulaciones femeniles frente a la estulticia masculina, la pobreza o la delincuencia que atenazan la sociedad de su momento. Como he escrito anteriormente, de poco vale trazar una evolución temática o estilística de una pieza a otra, pues es sabido que Salas se rigió por un criterio de variedad y no de coherencia, y que esta tendencia a unir textos dispares, que define toda su producción artística -más de setenta y cinco piezas - respondió también a su mermado capital económico y a las oportunidades que se le ofrecieron para sacar sus textos al mercado ${ }^{10}$. No es este el legado, sin embargo, de un escritor estrictamente moralizante, como tampoco nos encontramos ante lo que hoy se consideraría un cronista de literatura social atento a los acontecimientos del momento, como sí lo fueron sus coetáneos Quevedo, Liñán y Verdugo o Suárez de Figueroa. Las pullas y bromas de Salas rara vez son dirigidas a tal o cual personaje histórico, pues por lo general se construyen a partir de esquemas heredados, con arquetipos sociales en su punto de mira que muchas veces son atacados desde marcos narrativos como el viaje cósmico, la revisión del mito o la irrealidad del sueño. Sin embargo, lo que sí es cierto es que su legado nos resulta enormemente informativo como documento histórico, ya que no deja de ser una crónica muy personal de la España del siglo XVII y, en concreto, del Madrid del tercer y cuarto Felipe. Y esto se aprecia también en su producción teatral: el humor y el desencanto serán constantes tanto en sus comedias en ver-

7. Para un rastreo de las influencias e inspiraciones en Salas, ver LaGrone 1941, 1942, 1945. El primero de los artículos, dedicado a la materia celestinesca en Salas, tan solo dedica unos breves párrafos ( $p$. 450) a la pieza que nos ocupa.

8. La bibliografía sobre el mundo universitario en esta época es abundante. Para una aproximación general a la historia social de la enseñanza universitaria en España desde los siglos XVI a XVIII, ver Kagan, 1974.

9. Salas Barbadillo, La escuela de Celestina.

10. Ver, a este respecto, Peyton, 1973; Brownstein, 1974; García Santo-Tomás, 2008. 
so como en las tres más importantes que escribirá en prosa -a saber, El sagaz Estacio, marido examinado, La sabia Flora malsabidilla y El cortesano descortés, publicadas en el bienio de 1620-1621- y con las que, acaso también por su feliz contemporaneidad, la pieza aquí estudiada guarda muchas similitudes ${ }^{11}$.

La escuela de Celestina, dividida en tres actos y de una extensión cercana a la habitual -2.663 versos, en su mayoría octosilábicos-, se concibe, según explica Salas a don Juan de la Cueva y Mendoza en la dedicatoria, como una «comedia breve», como teatro para ser leído, con unos contenidos más cercanos a la sátira social que a temas como el honor o el amor típicos del drama auriseculari2. Carece de un argumento definido, así como de aquellas coordenadas típicas del género acotadas por Lope en su Arte nuevo tanto en lo estructural -exposición, nudo, desenlace, intrigas secundarias... - como en lo temático, hasta el punto de que sus personajes terminan la comedia como empezaron, «ni plus riches, ni plus pauvres, ni mariés, ni guéris de leurs défauts» ${ }^{13}$. Esta libertad a la hora de manipular los cánones del tiempo produce una serie de efectos dramáticos muy personales, derivados, por ejemplo, de la inserción de teatro breve -bailes, seguidillas, entremeses - dentro de cada «Jornada» en una estructura de cajas chinescas en donde el espectador puede disfrutar viendo a los personajes reaccionando también como espectadores. Y es que La escuela de Celestina es, ante todo, una meditación sobre la naturaleza de lo representado y sobre la transmisión adulterada del conocimiento, que en última instancia produce una inevitable crisis, escenificada en una caída que no solo es moral, sino que aquí, y en abierto homenaje al modelo primigenio, también lo será física. Si la comedia áurea nos ofrece todo un catálogo de tramas de marcada horizontalidad -con entradas y salidas frecuentes, con personajes corriendo por el tablado, con trayectos de un pueblo a otro, de una habitación a otra...-, Salas opta ahora por una plasticidad más orientada hacia lo vertical, escenificada en movimientos de arriba abajo a cargo de personajes que revelan así su calibre moral, su hegemonía en escena, su influencia en la comunidad y su capital social, tanto real como imaginado.

Esta verticalidad cargada de simbolismo pero también de literalidad se materializa en mujeres que reflexionan sobre cómo ascender de forma más eficaz en la sociedad cortesana manejando sus propias reglas del juego -y la idea de eficacia es seminal en este caso, pues late tras las enseñanzas que se transmiten en escena, en donde importa tanto lo que se elige como lo que se evita. La prostitución y sus artes configuran uno de los hilos centrales de la pieza, que en cierta manera conecta con los debates en torno al fenómeno de la mancebía ejercitada sin control legal, y cuyas consecuencias sociales eran evidentes en estos años en los que Ma-

11. Para un estudio pormenorizado de estas tres comedias en prosa, ver García Santo-Tomás, 2004. 12. No considero que pueda entrar esta obra en la categoría de las «comedias burlescas», a pesar de su extensión, del metro abundantemente utilizado (octosílabo), de ciertos recursos cómicos, de la utilización de los elementos paródicos con una obra emblemática como referencia... Dejo a especialistas en este género como Ignacio Arellano, Luciano García Lorenzo, Carlos Mata o Frédéric Serralta el adecuado acercamiento a esta obra para reflexionar en torno a ello.

13. Arnaud, 1977, p. 569 
drid había vuelto a ser sede gubernamental ya de forma definitiva (1606) ${ }^{14}$. Salas se había iniciado en este territorio con su conocida novelita picaresca La hija de Celestina (1612; publicada en versión ampliada dos años después como La ingeniosa Elena), en la cual su protagonista Elena se constituía como un personaje típicamente marginal que vivía de la burla y el engaño, del hurto y del desplazamiento continuo para salvaguardar las apariencias. El viaje narrativo, ausente ahora, situaba a sus protagonistas en algunos de los centros urbanos más homenajeados del momento como Toledo, Sevilla o Madrid. Las huidas y los encuentros fortuitos dotaban a la pieza de un especial dinamismo que maduraría luego en otras novelas posteriores como Teresa de Manzanares de Castillo Solórzano o El diablo cojuelo de Vélez de Guevara, con el viaje como marco narrativo. Gregory LaGrone sostuvo ya en su momento que, en La escuela de Celestina, «[T]he portion that concerns the lessons given by Celestina to her disciples is merely an amplification of the novel in tercets, La Madre, included in La ingeniosa Elena» ${ }^{15}$. Pero los múltiples recursos novelísticos que le ofrecen las nuevas y cambiantes realidades urbanas, y en particular las concernientes al ámbito femenino, harán que Salas sustituya el nomadismo de su Elena de principios de década por la urbanidad de una serie de damas de vidas mucho más comprometidas con sus roles sociales, con un mayor dominio de su entorno y una mayor sabiduría. Astutas cortesanas como Flora ( $L a$ sabia Flora, malsabidilla), Marcela (El sagaz Estacio, marido examinado) o Cristina (El cortesano descortés), creaciones ya plenamente integradas en el tejido citadino -madrileño, en la mayoría de las veces-, convertirán el espacio doméstico en escenario de numerosas peripecias en las que sus pares masculinos saldrán casi siempre mal parados ${ }^{16}$. No muy lejano será el escenario construido aquí: las tres discípulas de Celestina serán las prostitutas Flora, Beatriz y Cristina, pretendidas por cuatro galanes muy diferentes: Laurencio, amante del gusto de Flora; Alejandro, mercader de ropa que, se nos dice, tiene «tiendas» ${ }^{17}$, y al que Salas define como "amante del gasto de Flora»; Julio, médico "galenista» ${ }^{18}$, amante de Cristina; y don Felicio, caballero confiado y presuntuoso amante de Beatriz ${ }^{19}$. Gusto y gasto son dos términos deliberados en Salas, pues formarán una de las dicotomías seminales de las enseñanzas transmitidas por la vieja docta a sus discípulas, en cuanto que reflejan un fenómeno muy atractivo para los prosistas del momento, y que había contado con un precedente excelso ya en una novela como La gitanilla cervantina: la disciplina y el orden irrenunciable para la superación personal en el uni-

\footnotetext{
14. Sobre el fenómeno de la prostitución en esta época, véase por ejemplo Carrasco, ed., 1994; Deleito y Piñuela, 1948; Temprano, 1995; Rioyo, 2003, especialmente los capítulos que le dedica al reinado del cuarto Felipe. Para el caso sevillano, Moreno Mengíbar y Vásquez García, 1997. Tangencial, pero interesante, es la reciente compilación de Barbeito, ed., 1992.

15. LaGrone, 1941, p. 250.

16. Este fenómeno ha sido explorado en fechas recientes en estudios como los de Romero-Díaz, 2002; Cirnigliaro, 2015.

17. Salas Barbadillo, La escuela de Celestina, p. 49.

18. Salas Barbadillo, La escuela de Celestina, p. 50.

19. Cito por número de página. He manejado la única edición moderna con la que contamos, a cargo de Rodríguez de Uhagón, 1902, y en la que no se numeran los versos. He actualizado la ortografía y puntuación a criterios modernos.
} 
verso marginado de los desposeídos dentro de una sociedad abocada a la entropía. En ambos casos -en el de Monipodio tanto como en el de Celestina- el soporte del libro, el seguimiento literal de la ley escrita, será fundamental para el mantenimiento de este orden como garantía de supervivencia.

Así se nos indica ya desde el inicio de la pieza, la cual se abre con «la madre Celestina» portando un libro de su antecesora, «que escribió para su tiempo / con astuta sutileza» ${ }^{20}$. Esta alusión en el primero de los versos a un periodo histórico determinado es clave para entender los objetivos de la vieja maestra, pues sus enseñanzas están impregnadas de una urgencia muy evidente, de unos saberes muy anclados en su momento. Las lecciones desde la cátedra que da Celestina están encaminadas a la formación de las jóvenes en una realidad histórica muy diferente de la de 1500 y, gracias a ellas, Salas se brinda la oportunidad de reflexionar sobre lo que le rodea, sobre el declive moral y social de 1620. El deseo de la vieja es que todo este conocimiento práctico se transmita a la generación siguiente dotando a las mujeres de unas herramientas específicas para unas circunstancias nuevas en donde ciertos bienes de consumo -ropa, coches, manjares exóticos...- definen nuevas relaciones inter-genéricas y nuevos mecanismos de medro.

Desde el inicio Celestina es consciente del peso histórico de su linaje, de una estirpe en la cual la tecnología de la palabra debe ser puesta en práctica para lograr el mejor de los réditos:

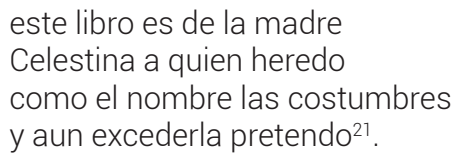

Fernando de Rojas se constituye entonces como el modelo a seguir, pero también, según reza el pasaje, como paradigma a ser superado, pues aunque «[N]o le podemos negar / que escribió para su tiempo / con astuta sutileza» ${ }^{22}$, lo que realmente se busca es evitar la caída sufrida por los Calisto y compañía gracias a la correcta divulgación de unos saberes que tan solo pueden ofrecerse ex catedra -ya no estamos ante una tragicomedia, sino ante una pieza rigurosamente cómica. El amor se convierte en «razón de estado» ${ }^{23}$, y la vieja anuncia entonces que «más que bellos semblantes / almas políticas precio» ${ }^{24}$ pues su «escuadrón de Venus» ${ }^{25}$, como veremos pronto, debe ser instruido con cuidado en la elección de la clientela adecuada. Esta acuñación de «almas políticas» es fundamental a la hora de entender el sentido de la comedia, en la medida en que Celestina busca inculcar en sus doctorandas una auto-conciencia que no debe ser nunca abandonada, una idea de lo político que conectaba con la teoría expresada en la época en manuales de educación para los

20. Salas Barbadillo, La escuela de Celestina, p. 20

21. Salas Barbadillo, La escuela de Celestina, p. 20

22. Salas Barbadillo, La escuela de Celestina, p. 20.

23. Salas Barbadillo, La escuela de Celestina, p. 20

24. Salas Barbadillo, La escuela de Celestina, p. 20

25. Salas Barbadillo, La escuela de Celestina, p. 86. 
gobernantes: las jóvenes deben ser siempre estratégicas en sus decisiones, y disponer así de unas serie de tácticas para ser utilizadas frente a las imposiciones del poderoso, sea cual sea el tipo de cliente; y siempre primando la inteligencia -manifestada en conductas como la disimulación - sobre la belleza, dado que

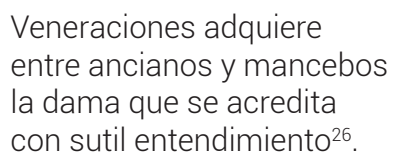

Con el fin de escenificar de la mejor manera el espacio de esta 'escuela de la vida', Salas imagina un «jardín de amor» ${ }^{27}$ para el deleite de los personajes masculinos que acuden a él. La broma consistirá en representar un entremés en el que las tres rameras se enzarcen en una pelea, para que Beatriz acabe cayendo en un pozo. El espectáculo, diseñado para engañar al presumido Felicio, contará con la complicidad de los otros personajes masculinos, hasta el punto de que Laurencio comentará que «[I]nquietud que es tan fogosa / suspende» ${ }^{28}$, subrayando irónicamente el sentido de maravilla que le produce todo este engaño desplegado ante sus ojos.

Como parte de lo que la propia Celestina define como «tramoya artificiosa» ${ }^{29}$, el madrileño nos conduce entonces a un primer 'descenso' cuando la joven Beatriz cae al pozo fingido, cuya profundidad Felicio no llegará a ver nunca. Tras pagar éste por el «rescate», la vieja recupera a Beatriz como por encanto en un ascenso que recuerda el de don Quijote en la cueva de Montesinos. Esta Beatriz transformada - «un espíritu [...] en sus brazos me cogió» ${ }^{30}$-, que vuelve del «espantoso averno» ${ }^{31}$, enarbola entonces una crítica social muy semejante a la que aparecerá en piezas posteriores de Salas como Don Diego de noche (1623) o Coronas del Parnaso (1635). La diatriba, basada en los personajes que vio en el inframundo, se inicia con los escribanos, y continúa con un cornudo, un boticario, un mohatrero, dos aceiteros y un valentón, personajes, todos ellos, endemoniados. Toda esta sátira sirve para dar entrada a algo muy diferente, a saber, la parodia académica que pronto coronará a Cristina como doctora: Julio primero, y Alejandro después, entablan un duelo retórico con ésta, quien les distribuye a cada uno un papel con una tesis - «mucho da quien pide celos»y «no hay dicha sin dinero»- que ellos deben refutar. En esta parodia universitaria Celestina aparece «con tocas de viuda y un libro en la mano» ${ }^{32}$ tal y como lo hacía en la versión de Rojas. Sus conclusiones al final del primer acto no son sino una transposición de los conocidos ejercicios universitarios, con un intercambio de pareceres en el que Cristina se defiende de los embates de sus adversarios con una serie de inteligentes y bien razonados contra-argumentos. En ambos casos la joven sale victoriosa, pues su lógica se

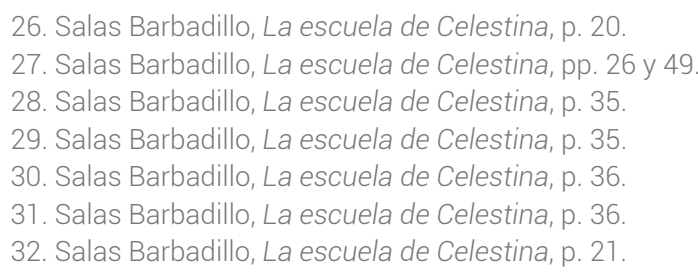


impone a la de sus rivales, y con ello supera una prueba más en sus 'oposiciones' académicas ante su maestra Celestina, que observa como su discípula está ya casi lista para ser orlada. Este será, de hecho, el proceso a seguir por la joven ramera para poder graduarse: el rector -en este caso, Celestina- ha propuesto en cierta manera la cuestión doctoral, a la que ha tenido que contestar el graduando.

La estructura impuesta por los cánones universitarios se mantiene en la Jornada central de la pieza. Celestina sube otra vez a su cátedra, e imparte su segunda lección magistral: para elegir amante, indica, es mejor la «comodidad» que «el buen gusto» " 33 y por tanto un viejo con dinero puede ser una buena opción, pues «disfaman menos», con la ventaja añadida de que «si están en edad caduca / que solo en ver se deleitan $»^{34}$-es decir, no requieren encuentro carnal alguno. Para la vieja, es también preferible que no tengan dientes, pues así pagan la merienda pero no pueden comerla; más aún, los viejos desdentados no podrán murmurar nunca, porque "que mal hablara entre dientes / quien apenas tiene muelas» ${ }^{35}$. Recomienda entonces a las tres jóvenes que busquen hombres que no sean afeminados, y que les miren bien las manos para ver si están demasiado cuidadas, pues «mucho estudio en ellas ponen / grandes cuidados les cuestan» ${ }^{36}$. Les previene también contra los galanes excesivamente atildados, no sea que acabe tratándose de homosexuales «que saben volver espaldas / y que reciben en ellas» ${ }^{37}$, entrando así en los debates en torno a la excesiva molicie de los nuevos cortesanos que tanto preocuparon en la España del Barroco ${ }^{38}$. Les recuerda, por tanto, que busquen mozos 'de verdad', pero que el trato sea temporal para no atarlas a ninguno de ellos, es decir, que el cliente «goce, pague, y más no vuelva» ${ }^{39}$. Importante es también que eviten borrachos, que no suban a los coches, que huyan de los escribanos y alguaciles pues son avaros y corruptos, y que procuren no ser pagadas con comida, porque «un puñado de doblones / es la mejor colación» ${ }^{40}$. Les sugiere, por el contrario, la compañía de mercaderes, y si tienen tiendas mejor, pues de allí podrán sacar prendas gratis, e insiste que recuerden que con dinero podrán siempre elegir su propia libertad: «solo al oro soleniza» ${ }^{41}$. Se pasa así del sistema tardo-feudal de la Celestina original a uno ya proto-capitalista en el que la remuneración debe hacerse con moneda, en formas de subsistencia -como las referidas a los regalos de los mercaderes- que resultan muy modernas. La vieja les aconseja, en suma, que sean siempre precavidas, que sean almas políticas, ofreciéndoles un modo específico de conocimiento. Así lo hará bajándose de la cátedra y acercándose a su auditorio, como solía ser costumbre en muchos casos:

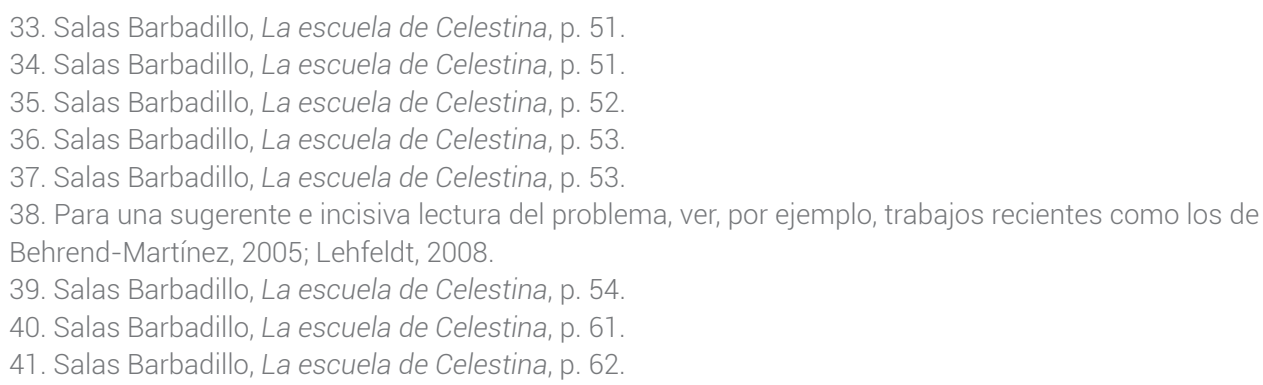




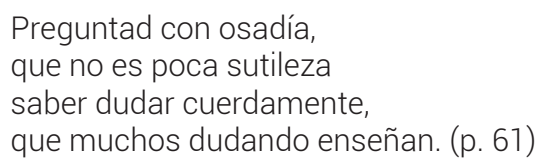

Y cuando las chicas elogian a Celestina por haber leído tanto desde niña y por dar tan buenos consejos, ella responde, con un solipsismo muy barroco que la sitúa ya lejos de estas prácticas, que "[S]é que no sé» ${ }^{42}$.

La tercera jornada escenifica la lección final de Celestina, «unas estafas modernas / en mi ingenio fabricadas ${ }^{43}$ ya más acordes a los tiempos que corren. Cristina se gradúa de doctora al día siguiente, pero antes deben de darse una serie de rituales. En un divertido entremés se escenifica la caída a los infiernos del "vano hidalgote» ${ }^{44}$ de la segunda parte del título de la pieza, de este presuntuoso y arrogante Felicio. La crítica no es nueva, como tampoco lo es el personaje, que se asemeja en su pompa y vacuidad al cortesano descortés que daba título a la novela homónima, a ese don Lázaro que, en su obsesión por mantener puesto su sombrero y no saludar a nadie en sus paseos por la ciudad, acababa siendo ridiculizado por sus vecinos. Este Felicio es ahora un vano simplón preocupado por signos visibles de su discurso y de su atuendo -como serán las cruces de las tres órdenes de caballería que lleva en el pecho-, y que se da el lujo de insultar a autoridades como Séneca o Cicerón, a quienes desprecia en su ignorancia. La representación académica consistirá ahora en un duelo dialéctico, como los que se entablaban en las universidades, entre dos personajes: Julio, el médico amante de Cristina, se viste de demonio, y desafía a don Felicio, quien afirma superar al demonio en la hermosura del rostro «y en el sutil ingenio». Seguidamente elevan al presumido hasta la parte más alta del teatro y amenazan con despeñarlo, haciendo obviamente alusión al modelo original de Rojas. La brevísima acción esbozada se resuelve lingüísticamente decantándose por Felicio, quien siendo «más presumido que el demonio» ${ }^{45}$ le gana la partida a Julio. Esta variación de los cánones de la comedia queda corroborado al final, al comentar la protagonista:

$$
\begin{aligned}
& \text { La Escuela de Celestina } \\
& \text { se acabó sin que la alegren } \\
& \text { castañetas de una boda, } \\
& \text { soltera farsa a ser viene }{ }^{46} \text {. }
\end{aligned}
$$

El concepto de «soltera farsa», como nos recordaba Antonio Cao ${ }^{47}$, no sólo señala la ausencia de bodas como final feliz de tantísimas comedias, sino que también sugiere un paródico afán de autodefinición genérica, en el sentido de farsa única.

42. Salas Barbadillo, La escuela de Celestina, p. 65.

43. Salas Barbadillo, La escuela de Celestina, p. 90.

44. Salas Barbadillo, La escuela de Celestina, p. 91.

45. Salas Barbadillo, La escuela de Celestina, p. 94.

46. Salas Barbadillo, La escuela de Celestina, p. 99.

47. Cao, 1992. 
Estamos, por tanto, ante tres largos monólogos didácticos, uno en cada Jornada, en que desde su cátedra la vieja ofrece a sus discípulos instrucción para doctorarse en la más antigua de las profesiones. Su conocimiento, como dirá Alejandro, es el conocimiento de la calle, un conocimiento infinito como la propia vida, ya que

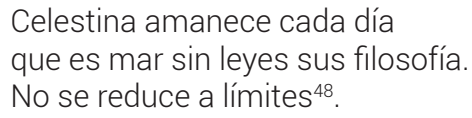

No cabe duda de que en Salas brilla la riqueza del lenguaje dramático, que va a jugar un papel primordial en el desenlace de la broma a don Felicio el hidalgote. El aluvión de pullas que recibe por parte de Julio se aproxima a los gallos universitarios, como prueba aproximada de una cultura verbal, cercana a formas como la del arte de motejar y dar matraca. Pero lo que la pieza realmente nos ofrece es una clara escenificación, en una parodia llevada a sus más degradantes extremos, de los llamados vejámenes universitarios. El vejamen se daba el día anterior a la ceremonia de magisterio y la práctica de trasladar estas ceremonias al teatro no era exclusiva de Salas, pues se dio también en otros autores como el propio Lope, quien introdujo un vejamen en su pieza La inocente sangre, y aludió en El alcalde mayor a otro a través de sus personajes Pánfilo y Verino. Tenemos aquí los frutos de lo que Aurora Egido, en la Introducción que le dedica al estudio sobre este fenómeno realizado por Abraham Madroñal, ha definido como «una retórica viciosa, frívola y mordaz que no teme caer en la burla fácil ni en la chocarrería con tal de poner en ridículo a la persona, exagerando sus defectos físicos y morales, gracias a la palabra y a los gestos» ${ }^{49}$.

Salas captura en la pieza el sentido paródico del vejamen de grado, que no era sino una de las varias parodias de actos académicos serios que existían en la época -muchas de ellas como las conclusiones o repeticiones burlescas dentro del mismo ámbito escolar. En la segunda mitad de la tercera Jornada, la prostituta Flora hace finalmente el vejamen final con todos los personajes presentes, incluida la «rectora Celestina» ${ }^{50}$, y en él expone los méritos de Cristina, como por ejemplo el hecho de que supo vender su virginidad dos veces. Se trata de un vejamen de grado previo a la imposición de la borla de doctor, que se le concede a la prostituta por la propia vieja catedrática, quien le pide entonces a la orlada que financie una corrida de toros, como se hacía, comenta Salas, en la Universidad de Salamanca. Cristina le responde que para cornudos ya tienen a los cuatro pretendientes, y que se divertirán con ellos, pues toros o maridos, como dice uno de los músicos, «todo es lo mismo» ${ }^{51}$, y como dice otro, jugando con la bisemia del término, «todos son mansos ${ }^{52}$. Nadie parece quedar, entonces, a salvo: Salas recoge en esta pieza elementos de otras parodias, como las del sistema de oposiciones, con la burla de los

48. Salas Barbadillo, La escuela de Celestina, p. 76.

49. Salas Barbadillo, La escuela de Celestina, p. 21.

50. Salas Barbadillo, La escuela de Celestina, p. 94.

51. Salas Barbadillo, La escuela de Celestina, p. 97.

52. Salas Barbadillo, La escuela de Celestina, p. 97. 
doctores que intervienen en ellas, y que fueron típicas del teatro de colegio como el jesuítico en el cambio de siglo. El cierre de la pieza, un tanto abrupto para los cánones teatrales del momento -y Salas anuncia, recordemos, una segunda parte- se justifica sin embargo si seguimos la lógica de la temporalidad de la pieza, pues los tres días de sus tres Jornadas le permiten ser fiel al ritual universitario: un exordio (captatio) en el que se nos presenta el marco prostibulario; las burlas (vituperatio) que incluyen la descripción moral del vejado y la crítica burlesca a otros doctores del claustro; y las veras (laudatio) en las que se incidía en la aptitud intelectual y moral del nuevo doctor, antes del cierre.

\section{Abraham Madroñal ha indicado que}

el vejamen se sitúa a medio camino entre la prosa y el verso, entre la oralidad y la escritura, entre la lectura y la representación, y se utiliza para destacar de forma burlesca los defectos de una persona o sus logros y actividades, a sabiendas de que no se dice toda la verdad y de que lo que se expresa es una caricatura de la realidad ${ }^{53}$.

A través de las intervenciones de las prostitutas y de los galanes, la pieza capta a la perfección el sentido de oralidad de estos ceremoniales, así como la búsqueda de la risa y el poder visual de la escenificación. Vemos, por consiguiente, cómo esta escuela celestinesca enmarca el esquema de la parodia, tanto como el hidalgo presumido cataliza la sátira y la burla. Desde esta doble naturaleza Salas nos invita a meditar sobre asuntos candentes como el papel de la alta cultura frente a la 'escuela de la vida' en la sociedad barroca, sobre el mismo ceremonial que la rodea y consagra y sobre, en última instancia, la podredumbre moral que define su entorno ${ }^{54}$. Pero lo que realmente nos enseña La escuela de Celestina es a reflexionar sobre la fertilidad teatral de un modelo que contaba ya con más de un siglo de vida, y que por sus propias características podía adaptarse a los tiempos nuevos con la modificación de ciertos elementos y el añadido de ingredientes nuevos que dieran cuenta de las nuevas realidades sociales; unas realidades urbanas que, en la España barroca, habían alcanzado nuevas cotas de pesimismo y desengaño, incluso para los estratos considerados más 'libres' de su tejido social. En última instancia, la pieza resulta de gran valía para todo aquel interesado en la historia intelectual de los Siglos de Oro, en la medida en que refleja eso que Harold Bloom llamo «anxiety of influence $»^{55}$ en un escritor tan poroso como Alonso de Salas Barbadillo. Esta influencia es ahora una ventaja y no una limitación, pues mediante el recurso de la parodia el narrador madrileño nos recuerda que, si la cultura oficial no logra sus objetivos, habrá que acudir a la escuela de la vida con su biblioteca celestinesca, y volver así al pasado como maestro del presente.

53. Madroñal, 2005, p. 27.

54. Sobre el funcionamiento de la sátira en Salas, ver, por ejemplo, Place, 1926; Senzier, 1978.

55. Bloom, 1997. 


\section{BIBLIOGRAFÍA}

Arellano, Ignacio, «La Celestina en la comedia del XVII», en Celestina: recepción y herencia de un mito literario, ed. Gregorio Torres Nebrera, Cáceres, Universidad de Extremadura, 2001, pp. 51-72.

Arnaud, Emile, La vie et l'oeuvre de Alonso Jerónimo de Salas Barbadillo: contribution a l'etude du roman en espagne au debut du XVIIe siecle, Toulouse, Université de Toulouse-Le Mirail, 1977, 3 vols.

Barbeito, Isabel (ed.), Cárceles y mujeres en el siglo XVII, Madrid, Castalia, 1992.

Behrend-Martínez, Edward, «Manhood and the Neutered Body in Early Modern Spain», Journal of Social History, 38, 4, 2005, pp. 1073-1093.

Bloom, Harold, The Anxiety of Influence: A Theory of Poetry, Oxford, Oxford University Press, 1997.

Brownstein, Leonard, Salas Barbadillo and the New Novel of Rogues and Courtiers, Madrid, Playor, 1974.

Cao, Antonio, «La Anticomedia de Salas Barbadillo. Transposición genérica y desplazamiento de la figura mítica», en Actas del X Congreso de la Asociación de Hispanistas, I-IV, ed. Antonio Vilanova, Barcelona, Promociones y Publicaciones Universitarias, 1992, pp. 799-812.

Carrasco, Raphaël (ed.), La prostitution en Espagne: de l'époque des rois catholiques à la lle République, Paris, Les Belles lettres, 1994.

Cassol, Alessandro, «Salas Barbadillo, de. Teatro y poesía», en Diccionario filológico de literatura española. Siglos XVI y XVII, vol. II, coord. Pablo Jauralde, Madrid, Castalia, 2011, pp. 350-357.

Cirnigliaro, Noelia, Domus. Ficción y mundo doméstico en el Barroco español, Londres, Tamesis, 2015.

Cauz, Francisco, La narrativa de Salas Barbadillo, Buenos Aires, Colmegna, 1977.

Deleito y Piñuela, José, La mala vida en la España de Felipe IV, Madrid, EspasaCalpe, 1948.

García Santo-Tomás, Enrique, «Salas Barbadillo, materia de teatro», Revista Canadiense de Estudios Hispánicos, 29, 1, 2004, pp. 169-186.

García Santo-Tomás, Enrique, Modernidad bajo sospecha: Salas Barbadillo y la cultura material del siglo XVII, Madrid, CSIC, 2008.

González Echevarría, Roberto, La prole de Celestina. Continuidades del Barroco en las literaturas españolas e hispanoamericanas, Madrid, Colibrí, 1999.

Heugas, Pierre, «La Celestina» et sa descendence directe, Bordeaux, Institut d'Études Ibériques, 1973. 
Kagan, Richard. Students and Society in Early Modern Spain. Baltimore, The Johns Hopkins University Press, 1974.

LaGrone, Gregory, «Salas Barbadillo and the Celestina», Hispanic Review, 9, 4, 1941, pp. 440-458.

LaGrone, Gregory, «Quevedo and Salas Barbadillo», Hispanic Review, 10, 1942, 3, pp. 223-243.

LaGrone, Gregory, «Some Poetic Favorites of Salas Barbadillo», Hispanic Review, 13, 1, 1945, pp. 24-44.

Lehfeldt, Elizabeth, «Ideal Men: Masculinity and Decline in Seventeenth-Century Spain», Renaissance Quarterly, 61, 2, 2008, pp. 463-494.

Madroñal, Abraham, «De grado y gracias». Vejámenes universitarios de los Siglos de Oro, Madrid, CSIC, 2005.

Moreno Mengíbar, Andrés y Francisco Vásquez García, «Poderes y prostitución en España (siglos XIV-XVII): El caso de Sevilla», Criticón, 69, 1997, pp. 33-49

Peyton, Myron A., Alonso Jerónimo de Salas Barbadillo, New York, Twayne Publishers, 1973.

Place, Edwin B., «Salas Barbadillo, Satirist», Romanic Review, 17, 1926, pp. 230-242.

Rioyo, Javier, La vida golfa, Madrid, Aguilar, 2003.

Romero-Díaz, Nieves, Nueva nobleza, nueva novela. Reescribiendo la cultura urbana del Barroco, Newark, DE, Juan de la Cuesta, 2002.

Salas Barbadillo, Alonso Jerónimo de, Comedia de La escuela de Celestina y el hidalgo presumido, ed. Francisco R. de Uhagón, Madrid, Fortanet, 1902.

Salas Barbadillo, Alonso Jerónimo de, La hija de Celestina, ed. Enrique García Santo-Tomás, Madrid, Cátedra, 2009.

Senzier, Guy, «Caracteres y formas de la sátira en Salas Barbadillo», en Melanges à la mémoire d'André Joucla-Ruau, ed. Jean-Filippi Chalon et al., Aix-en-Provence, Université de Provence, 1978, pp. 1109-1118.

Temprano, Emilio, Vidas poco ejemplares: viaje al mundo de las rameras, los rufianes y las celestinas (siglos XVI-XVIII), Madrid, Ediciones del Prado, 1995.

Torres, Lucas, «Hijas e hijastras de Justina: venturas y desventuras de una herencia literaria», en Memoria de la palabra: Actas del VI Congreso de la Asociación Internacional Siglo de Oro, II, ed. María Luisa Lobato y Francisco Domínguez Matito, Madrid/Frankfurt, Iberoamericana/Vervuert, 2004, pp. 1763-1771. 
